Titulillo: LA VISIÓN DEL OTRO: HOMOSEXUALES INDOANTILLANOS EN LA ÉPOCA DE LA CONQUISTA

La visión del otro: homosexuales indoantillanos en la época de la conquista

Manuel A. Crespo Rodríguez

Universidad de Puerto Rico en Arecibo

Departamento de Ciencia Sociales

Concentración en Estudios Iberoamericanos

Dr. Carlos Altagracia 
LA VISIÓN DEL OTRO: HOMOSEXUALES INDOANTILLANOS EN LA ÉPOCA DE LA CONQUISTA

\section{Resumen:}

Este trabajo tiene como propósito sacar a la luz una interpretación de la homosexualidad indoantillana que es poco común. Los europeos arribaron al Nuevo Mundo con expectativas de encontrar riquezas y criaturas fantásticas. En ese frenesí se comenzó el proceso de la conquista de América. No obstante, ¿cómo se utiliza el discurso sobre la homosexualidad para identificar a ese otro al que le llaman indígena?

Palabras claves: indoantillano, homosexualidad, sodomía, Sodoma y Gomorra, acto nefando, Edad Media, europeos, españoles.

\footnotetext{
Abstract:

This work has the purpose of shedding light to a new interpretation of indoantillean homosexuality that is uncommon. The Europeans arrived at the New World expecting riches and fantastic creatures. In that frenzy began the process of the American conquest. Nevertheless, how the homosexuality discourse is used to identify the other that is called indigenous? Key words: indoantillian, homosexuality, sodomy, Sodom and Gomorra, heinous act, Middle Age, europeans, spaniards.
} 


\title{
LA VISIÓN DEL OTRO: HOMOSEXUALES INDOANTILLANOS EN LA ÉPOCA DE LA CONQUISTA
}

\section{Introducción}

\author{
"Menos Adictas al Estudio de la Cartografía, las Generaciones Siguientes \\ entendieron que ese dilatado Mapa era Inútil y no sin Impiedad lo entregaron a \\ las Inclemencias del Sol y los Inviernos". \\ — Jorge Luis Borges, Del rigor en la ciencia.
}

\footnotetext{
“A la historia la escriben los que vencen".

—Leopoldo Brizuela, Una misma noche.
}
"Si alguno se ayuntare con varón como con mujer, abominación hicieron; ambos han de ser muertos; sobre ellos será su sangre”.

-Levítico 20:13, Biblia Reina-Valera 1960

Durante mucho tiempo la homosexualidad ${ }^{1}$ ha formado parte de la historia de la humanidad, a veces de manera implícita y otras de manera explícita; a veces fue condenada y otras fue aprobada. Durante el proceso de descubrimiento y conquista de Hispanoamérica los europeos usurparon y esclavizaron indígenas gracias a la sacrosanta idea de la conquista. Esto se explica en la siguiente cita: “[...] el Estado fue para la Iglesia una suerte de caballo de Troya pues, así como el Estado necesitaba encubrir la conquista bajo la forma de evangelización la Iglesia realizará la evangelización sirviéndose de la conquista"2. Algunas personas defendieron la causa de los indios, pero esto implicaba sermonear sobre el Cielo y el Infierno:

\footnotetext{
Decid, ¿con qué derechos y con qué justicia tenéis tan cruel y horrible servidumbre aquestos indios? Con qué autoridad habéis hecho tan detestables guerras a estas gentes que estaban en sus tierras tan mansas y pacíficas, donde tan infinitas dellas, con muertos y estragos nunca oídos, habéis consumido. ¿Cómo los tenéis tan opresos y fatigados, sin dalles de comer ni curarlos en sus enfermedades que, de los excesivos trabajos
}

\footnotetext{
${ }^{1}$ En el Diccionario de la Real Academia Española aparecen dos significados de homosexualidad. El primero es "inclinación hacia la relación erótica con individuos del mismo sexo". La segunda definición, que es de mayor pertinencia en mi investigación, dice que la homosexualidad es la "práctica de dicha relación".

Recuperado de http://buscon.rae.es/drae/srv/search?val=homosexualidades

${ }^{2}$ Mires, Fernando (2007) La conquista de América: misión y conquista en Hispanoamérica. Buenos Aires: Libros de la Araucaria, pp.40, La cuestión del patriarca.
} 


\section{LA VISIÓN DEL OTRO: HOMOSEXUALES INDOANTILLANOS EN LA ÉPOCA DE LA CONQUISTA}

que les dais se os mueren, y por mejor decir, los matáis, por sacar y adquirir oro cada día? ¿Y qué cuidados tenéis de quien los doctrinen y conozcan a su Dios y criados, sean baptizados, oigan misa, guarden las fiestas los domingos? ¿Estos no son hombres? ¿No tienen ningunas ánimas racionales? ¿No sois obligados a amallos como a vosotros mismos? ¿Esto no entendéis? ¿Esto no sentís? ¿Cómo estáis en tanta profundidad de sueño, tan letárgicos, tan dormidos? Tened por cierto que en el estado en que estáis no os podéis salvar más que los moros y turcos que carecen y no quieren la fe de Jesucristo. ${ }^{3}$

La cita anterior muestra mi punto. Como muchos sabemos, Fray Bartolomé de las Casas fue defensor de las causas indígenas, pero su acercamiento no fue el mejor a la hora de defender a los nativos del Nuevo Mundo: de cualquier manera la evangelización implica la destrucción de las creencias indígenas, incluyendo su praxis. Cambiaría la manera que ellos tienen de percibir la sexualidad: tendrían que desistir de los deseos carnales que no le gustan a Jesucristo; tendrían que comenzar a seguir los mores cristianos; tendrían que cumplir con la sagrada institución del matrimonio.

No obstante, en la contemporaneidad se ha podido hablar mucho sobre las prácticas homosexuales y se han mantenido fervientes debates sobre ello ${ }^{4}$, sin embargo, ¿qué se sabe verdaderamente sobre la homosexualidad en los indígenas? Deberíamos considerar el vacío aparente de información ${ }^{5}$. Además de ello, en otros tiempos las personas eran perseguidas por cómo pensaban.

\footnotetext{
${ }^{3}$ De las Casas, Bartolomé (1875). Historia de las Indias. Madrid, libro III, pp. 366.

${ }^{4}$ Is the Catholic Church a Force for Good in the World?: Intelligence Squared. Youtube. Recuperado de http://www.youtube.com/watch?v=TUR4OH7_OPE

Same-Sex Marriage Debate: Gallagher vs. Corvino. Youtube. Recuperado de http://www.youtube.com/watch?v=2ZVA0vwHMQs

${ }^{5}$ Desde hace tiempo se han prolongado ideas de extinción indígenas a partir de la interpretación literal de la conquista europea. Inclusive, estas ideas se han mantenido en el Centro de Estudios Avanzados de Puerto Rico y el Caribe. Persisten en el argumento de la destrucción indígena a pesar de nuevos hallazgos arqueológicos y datos contundentes que le pueden añadir a un fervoroso debate. Algunas de las personas subestimadas por dicha politización fueron Oscar Lamourt-Valentín — su investigación lingüística es un aporte importante para entender el lenguaje indígena en Puerto Rico - y Dr. Roberto Martínez Torres — cuya investigación sobre el geoglifo en Utuado arroja luz a la supervivencia de indígenas en Puerto Rico más allá del siglo XVI.

Lamourt-Valentín, Oscar (n.d.). Análisis de las crónicas de Pané. Documento no publicado.

Martínez Torres, Roberto (n.d.). Catey.
} 


\section{LA VISIÓN DEL OTRO: HOMOSEXUALES INDOANTILLANOS EN LA ÉPOCA DE LA CONQUISTA}

Esta investigación tiene como propósito poner en claro la visión del europeo sobre los actos homosexuales de ese "otro" al que llamaban indígena. Asimismo, aunque hay menciones de actos homosexuales en varios lugares de América $^{6}$, este trabajo se centralizará en las Antillas $^{7}$. Para ello utilizo las crónicas españolas y francesas ${ }^{8}$. Dicho de otra manera, las crónicas serán el telescopio por el cual atisbo el universo indígena - como Galileo Galilei observando a Saturno con su rústico telescopio-, pues esas verdades no son autoevidentes: necesitan un observador; necesitan una interpretación. Así de oscuros fueron los estragos de la conquista.

\section{Datos contemporáneos sobre la homosexualidad}

Esta investigación — aunque es de índole histórico — es una explicación contemporánea de los acontecimientos entre europeos e indígenas respecto a las prácticas sexuales. Por ello debemos tener en claro lo que dice la psicología y la biología contemporánea al respecto. Como mencioné en la introducción, actualmente se han mantenido debates con respecto a la

\footnotetext{
${ }^{6}$ Encontré varias menciones sobre homosexualidad en Historia verdadera de la conquista de la Nueva España, de Bernal Día del Castillo, pero las menciones son en México. También existen varios artículos sobre indígenas homosexuales latinoamericanos en la época de la conquista, entre ellos Sexualidad en la cultura precolombina —de Veronique Miguel — y Sexualidad precolombina — de Hilda Rodas.

Por otro lado, en el libro Centering Animals in Latin American History, Martha Few y Zeb Tortorici comienzan relatando un acto de bestialismo perpetrado en Mérida por Pedro Na, un joven de catorce años: estaba practicando el acto sexual a un pavo. El pavo fue adquirido como evidencia pero murió días después por las heridas que sufrió en el intercambio carnal. El joven fue sentenciado a castración pública después de admitir haber fornicado con el pavo. Luego fue expulsado de Yucatán. Este caso, aunque no es de homosexualidad, presenta lo evidenciable de temas extraordinarios. Según el texto, si el pavo no hubiese muerto por las heridas que sufrió, lo hubiesen matado según los mandatos enunciados en Levítico.

${ }^{7}$ En esta investigación es utilizada la palabra indoantillano, que significa “indio de las Antillas" según el

Diccionario de la Real Academia Española.

Indoantillano. Diccionario de la Real Academia Española (n.d.). Recuperado de http://lema.rae.es/drae/srv/search?key=indoantillano

${ }^{8}$ De Oviedo, Gonzalo F. (n.d.) Historia General y natural de las India. Recuperado de http://www.archive.org/stream/historiageneraly01fern\#page/n7/mode/2up

Díaz del Castillo, Bernal (n.d.) Historia verdadera de la conquista de la Nueva España. Recuperado de http://www.historiadelnuevomundo.com/docs/Conquista-Nueva-Espana-Bernal-Diaz-del-Castillo.pdf

Cárdenas Ruiz, Manuel (1981). Crónicas Francesas de los Indios Caribes. Puerto Rico: Editorial Universidad de Puerto Rico.

Pané, Ramón (n.d.). Relación acerca de las antigüedades de los indios. Siglo Veintiuno Editores. Recuperado de http://inabima.gob.do/descargas/bibliotecaFAIL/Autores\%20Dominicanos/Fray\%20Ramon\%20Pane/Fray\%20Ramo n\%20Pane\%20-\%20Relacion\%20acerca\%20de\%20las\%20antiguedades\%20de\%20los\%20indios.pdf
} 


\section{LA VISIÓN DEL OTRO: HOMOSEXUALES INDOANTILLANOS EN LA ÉPOCA DE LA CONQUISTA}

homosexualidad. Esto quiere decir que durante mucho tiempo se ha acumulado información

sobre las prácticas homosexuales y se ha cuestionado con la rigurosidad del método científico. A continuación verán algunos datos.

En los últimos cien años han existido adelantos en definir lo que es la homosexualidad. Un gran avance sucedió en 1990, cuando la OMS determinó que la homosexualidad no era una enfermedad. Todavía prevalecen lagunas sobre el origen de la homosexualidad: existe un debate sobre si es un evento a priori del nacimiento, a posteriori o una imbricación entre las dos. Con todo y con eso, "la mayoría de los científicos en la actualidad acuerdan que la orientación sexual es más probablemente el resultado de una interacción compleja de factores biológicos, cognitivos y del entorno"9. También se ha demostrado que el fenómeno sucede en el reino animal ${ }^{10}$. De todos modos, no existe evidencia biológica contundente, o como lo dice Jokin de Irala: “cualquier trabajo científico debe valorarse atendiendo solamente a criterios científicos, y dichos criterios son suficientes para poder afirmar que no hay en la actualidad ninguna evidencia científica a favor de una teoría genética de la homosexualidad" ${ }^{11}$. Por otro lado, se han documentado prácticas homosexuales en casi todas las civilizaciones de la historia, desde los griegos y romanos ${ }^{12}$ hasta el medioevo ${ }^{13}$, el renacimiento ${ }^{14}$ y la actualidad.

\footnotetext{
${ }^{9}$ Orientación sexual y homosexualidad. American Psychological Association. Recuperado de http://www.apa.org/centrodeapoyo/sexual.aspx

${ }^{10}$ La homosexualidad en los animales. Ojocientífico.com. Recuperado de http://www.ojocientifico.com/4247/lahomosexualidad-en-los-animales

${ }^{11}$ De Irala, Jokin (n.d.). Comprendiendo la homosexualidad. Recuperado de http://www.pfox.org/ebook_homosex_jokin_irala.pdf

${ }^{12}$ Viñau Ena, Nacho (8/Julio/2008). Homosexuales en Roma y Grecia. Ambiente G. Recuperado de http://www.ambienteg.com/historia/homosexuales-en-roma-y-grecia

${ }^{13}$ Pellini, Claudio A. (n.d.). Homosexualidad y amor conyugal en la Edad Media. Planeta Sedna. Recuperado de http://www.portalplanetasedna.com.ar/edadmedia5.htm

${ }_{14}$ Anónimo (n.d.). Homosexualidad en la Florencia renacentista. Islaternura.com. Recuperado de http://www.islaternura.com/APLAYA/HOMOenHISTORIA/FLORENCIA/Antigua\%20Florencia\%20Mayo\%20200 4.htm
} 


\section{LA VISIÓN DEL OTRO: HOMOSEXUALES INDOANTILLANOS EN LA ÉPOCA DE LA CONQUISTA}

\section{Actos impuros: homosexualidad y sexualidad en el medioevo}

El término "homosexualidad" no existía en la Edad Media. Al momento presente, la palabra "homosexualidad" tiene un bagaje de conceptos que se pueden considerar contemporáneos: matrimonio, derechos LGBT o movimiento social. También tiene un bagaje negativo de conceptos: acto antinatural ${ }^{15}$, anticristiano o pecado. Esas ideas negativas sobre la homosexualidad se pueden trazar desde la Biblia ${ }^{16}$. Los españoles decían "sodomitas"17, "acto de sodomía"18 o "acto nefando" 19 para referirse a lo que conocemos modernamente como "homosexualidad", pero esto no implica que se referían exclusivamente a la homosexualidad. En el Génesis se encuentra el relato de Sodoma y Gomorra ${ }^{20}$. La moraleja del relato es que Dios condena todo acto lujurioso. Por ello destruye a Sodoma y Gomorra.

Ahora bien, continuando la línea de pensamiento del párrafo anterior, la siguiente cita de John Boswell es significativa, pues trata sobre aspectos homosexuales-eróticos de los musulmanes en la Edad Media. Aquí no la puedo discutir a fondo, pero los datos que tiene son consonantes con la temática:

\footnotetext{
No es extraño que los gays florecieran en las ciudades de España. Hasta cierto punto, esto podría atribuirse a las actitudes de la cultura islámica en general. Aunque el Corán y los primeros escritos religiosos del Islam sostenían actitudes moderadamente negativas respecto de la homosexualidad, la sociedad islámica en general ignoraba estas desaprobaciones y la mayoría de las culturas musulmanas trataron la homosexualidad con
}

\footnotetext{
${ }^{15}$ De "contranatural. [...] Contrario al orden de la naturaleza". Recuperado de http://buscon.rae.es/drae/srv/search?val=antinatural También existe el latinismo contra natura, que significa "contra lo natural". Recuperado de http://www.wikilengua.org/index.php/Latinismo

${ }_{16}$ Anónimo (n.d.) Biblia Reina-Valera 1960. Levítico 18 y 20; Romanos 1: 26-27; 1 Corintios 6: 1 Timoteo 1. Recuperado de http://www.biblegateway.com/

${ }^{17}$ Según el Diccionario de la Real Academia Española hay tres definiciones de sodomita. La primera denota que sodomita es persona "natural de Sodoma" y la segunda que es "perteneciente o relativo a esta antigua ciudad de Palestina". La tercera definición es más pertinente a la investigación: “3. adj. Que comete sodomía”. Recuperado de http://buscon.rae.es/drae/srv/search?id=fvsdfgQ5tDXX2CXpTFzg

18 “Sodomizar. (De sodomía). 1. tr. Someter a penetración anal”. Recuperado de http://lema.rae.es/drae/srv/search?id=bFeKNzSeKDXX2vRX8qyP

19 "Nefando, da. (Del lat. nefandus). 1. adj. Indigno, torpe, de que no se puede hablar sin repugnancia u horror. V. pecado nefando". Recuperado de http://buscon.rae.es/drae/srv/search?id=oRBivhg3KDXX23skXUCa

${ }^{20}$ Anónimo (n.d.) Biblia Reina-Valera 1960. Génesis 19. Recuperado de http://www.biblegateway.com/
} 


\section{LA VISIÓN DEL OTRO: HOMOSEXUALES INDOANTILLANOS EN LA ÉPOCA DE LA CONQUISTA}

indiferencia, cuando no con admiración. Casi sin excepción, las obras clásicas de la poesía y la prosa árabe, de Abú Nuwas a Las mil y una noches, trataron con respeto o aceptaron ocasionalmente a los gays y su sexualidad. La lengua árabe contiene un inmenso vocabulario de terminología erótica gay, con docenas de palabras sólo para describir diferentes tipos de prostitución masculina. En la poesía árabe de amor es una convención corriente el tono erótico con el que un hombre se dirige a otro; incluso los poemas escritos sobre o para mujeres emplean a menudo pronombres masculinos y metáforas de belleza masculina: no es raro encontrar poesía dedicada a una mujer en la que el objeto de afecto del poeta se elogia en términos tales como 'oscuro mostacho sobre perlados dientes blancos' o 'el primer vello aterciopelado sobre la damasquina piel'. Los poemas sobre el aspecto físico de la primera barba de un joven constituyen todo un género de poesía árabe. El que esta literatura y estos fenómenos sociales no sean simple reflejo de las restricciones sociales a la exhibición y admiración públicas de las mujeres queda demostrado por el hábito, en muchas zonas del mundo musulmán (especialmente en España), de vestir a las chicas bonitas para que parezcan muchachos bonitos, esto es, con el pelo corto y ropas masculinas: es obvio que las mujeres que participaban en esta insólita forma de travestismo estaban en disposición de que se las apreciara como mujeres.

En la España de la Alta Edad Media, esta tendencia se vio exagerada, si cabe. Era común toda variedad de relación homosexual, desde la prostitución al amor idealizado. La poesía erótica sobre relaciones ostensiblemente homosexuales constituye todo tipo de personas de todos los estamentos. Los reyes escribían poemas de amor a / o sobre sus súbditos masculinos y recibían a cambio poesía erótica.

Los poetas escribían versos de amor entre sí o los escribían a otros de condición más humilde. También la gente común repetía, aunque no componía, canciones que celebraban el amor y la sexualidad gays. Cuando al-Mutamid, rey de Sevilla en el siglo XI, escribió, refiriéndose a su paje, 'Lo hice mi esclavo, pero la humildad de su mirada me convirtió en su prisionero, de tal modo somos ambos y al mismo tiempo esclavo y señor uno de otro', expresaba un sentimiento con el que sus súbditos podían simpatizar y probablemente ellos mismo habrían compuesto o recitado versos similares. ${ }^{21}$

Por esta razón la homosexualidad en España fue bastante conocida: esto es lo que motiva al español a tratar de retomar sus tierras. Por eso el rol de los musulmanes es importante, puesto que se puede conocer de donde proviene la influencia erótica homosexual. Esto reverbera el

${ }^{21}$ Boswell, John (n.d.). Cristianismo, tolerancia y homosexualidad. Recuperado de http://www.pridesites.com/sacerdotesgay/CTSYH/SG-CTSYH-07.htm 


\section{LA VISIÓN DEL OTRO: HOMOSEXUALES INDOANTILLANOS EN LA ÉPOCA DE LA CONQUISTA}

planteamiento de Jaime Montes Norniella: “La Edad Media española fue una época

contradictoria, en la que se sucedieron períodos de intensa belicosidad y fanatismo intolerante con otros de gran avance cultural y tolerancia, por lo que la suerte de los homosexuales debió ser variopinta" 22 .

Recordemos que antes del 1492 hubo un conflicto entre españoles y musulmanes en el territorio español ${ }^{23}$. A este proceso se le conoce como reconquista ${ }^{24}$. En ese tiempo los cristianos se dedicaban a conquistar las tierras que les habían sido rebatadas por los musulmanes. Este proceso comienza en 711, cuando "la península Ibérica había estado casi en su totalidad bajo el dominio islámico"25. Termina en 1492, cuando la alianza de los reinos de Castilla y Aragón retoma la ciudad de Granada — en otras palabras, la ciudad se rindió. Por lo que se puede observar, la reconquista fue un período que tardó cinco largos siglos en culminarse. Así que este proceso alimentó la intolerancia de los españoles hacia los musulmanes.

Por lo tanto, la diversidad variopinta de la suerte de los homosexuales a la que se refiere Jaime Montes Norniella se debe en parte a los muladíes y mozárabes. Los muladíes fueron la población autóctona hispanorromana que se convirtió al Islam mientras que los mozárabes fueron quienes permanecieron en el cristianismo. Entre ellos también convivieron los judíos ${ }^{26}$.

Pese a ello, la visión condenatoria hacia las prácticas sexuales sigue hasta el Renacimiento $^{27}$. Además, es sorprendente la creatividad de las condenas en esta época. Es

\footnotetext{
${ }^{22}$ Norniella, Jaime M. (n.d.). Homosexualidad en la Edad Media Española. Recuperado de http://www.islaternura.com/APLAYA/HOMOenHISTORIA/HomoEdadMedia.htm

${ }^{23}$ Ocaña, Juan C. (2011). La conquista musulmana y los pueblos invasores. Historiasiglo20.org. Recuperado de http://www.historiasiglo20.org/HE/2a.htm

${ }^{24}$ Anónimo (27/noviembre/2009) .La España musulmana (711-1492) .Recuperado de http://www.cdechamps-lyceedelacroix.fr/spip.php?article97

${ }^{25}$ Ibid.

${ }^{26}$ Ibid.

${ }^{27}$ Anónimo (n.d.). Castigos a homosexuales en España durante el Renacimiento. Islaternura.com. Recuperado de http://www.islaternura.com/APLAYA/HOMOenHISTORIA/CastigosPARAhomosexualidad.htm
} 
LA VISIÓN DEL OTRO: HOMOSEXUALES INDOANTILLANOS EN LA ÉPOCA DE LA CONQUISTA

importante recalcar que el $28.8 \%$ de las condenas era el destierro. Los demás datos se pueden ver en la ilustración 1.

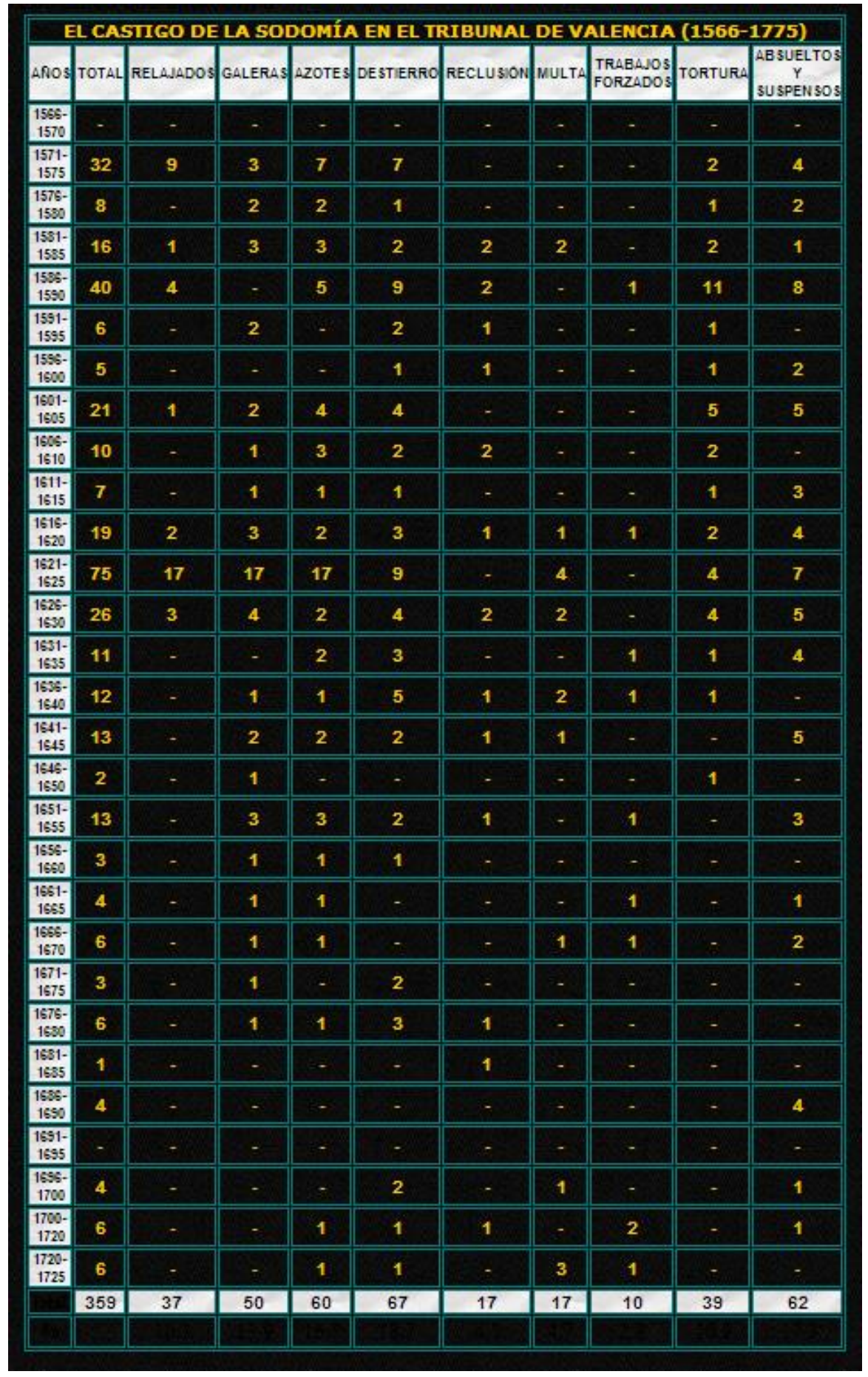

Ilustración 1: El castigo de la sodomía en el tribunal de Valencia (1566-1775).28

${ }^{28}$ Ibid. 


\section{LA VISIÓN DEL OTRO: HOMOSEXUALES INDOANTILLANOS EN LA ÉPOCA DE LA CONQUISTA}

Se puede observar que la cantidad de absueltos es casi igual que la cantidad de destierros.

Por lo tanto, las condenas más irrisorias, como los azotes, son números bastantes grandes.

Entonces, se puede deducir que eran más preferibles los azotes y las galeras que el trabajo

forzado o la tortura.

Consiguientemente, la Iglesia Católica era el estado por excelencia. Estaban los países

europeos en potencia —i.e. Francia, España, Portugal, Alemania—, pero la Iglesia era una fuerza que los abarcaba a todos e iba mucho más allá: era la representante de Dios en la Tierra.

Mantuvo su poder a toda costa y los que pensaban diferentes de ella fueron procesados. Su poder duró mucho tiempo. Logró procesar pensadores importantes como Giordano Bruno ${ }^{29}$ y Galileo Galilei $^{30}$.

Por otro lado, en el primer tomo de Historia de la locura en la época clásica, Michel Foucault argumenta lo siguiente respecto a las enfermedades venéreas en Francia:

\footnotetext{
El lugar de la lepra fue tomado por las enfermedades venéreas. De golpe, al terminar el siglo XV, suceden a la lepra como por derecho de herencia. Se las atiende en varios hospitales de leprosos: en el reinado de Francisco I, se intenta inicialmente aislarlas en el hospital de la parroquia San Eustaquio, luego en el de San Nicolás, que poco antes habían servido de leproserías. En dos ocasiones, bajo Carlos VIII, después en 1559, se les habían destinado, en Saint-Germain-des-Prés, diversas barracas y casuchas antes utilizadas por los leprosos. Pronto son tantas que debe pensarse en construir otros edificios "en ciertos lugares espaciosos de nuestra mencionada ciudad y en otros barrios, apartados de sus vecinos". Ha nacido una nueva lepra, que ocupa el lugar de la primera. Mas no sin dificultades ni conflictos, pues los leprosos mismos sienten miedo: les repugna recibir a esos recién llegados al mundo del horror. "Est mirabilis contagiosa et nimis formidanda infirmitas, quam etiam detestantur leprosi et ea infectos secum habitare non permittant." Pero si bien tienen
}

\footnotetext{
${ }^{29}$ Giordano Bruno. Agustín Celis Sánchez. Recuperado de http://www.agustincelis.com/GIORDANO\%20BRUNO.html

${ }^{30}$ García Álvarez, Miguel (n.d.). Sentencia de la Inquisición a Galileo. Recuerdos de Pandora. Recuperado de http://recuerdosdepandora.com/personajes/galileo-galilei/sentencia-de-la-inquisicion-a-galileo/
} 


\section{LA VISIÓN DEL OTRO: HOMOSEXUALES INDOANTILLANOS EN LA ÉPOCA DE LA CONQUISTA}

derechos de antigüedad para habitar esos lugares "segregados", en cambio son demasiado pocos para hacerles valer; los venéreos, por todas partes, pronto ocupan su lugar. ${ }^{31}$

En la cita se puede observar que los franceses tienen un miedo exacerbado por la sexualidad. Claro, en este caso se refería a las enfermedades venéreas, pero el repudio es tan grande que ni siquiera los leprosos quieren que convivan entre ellos. La enfermedad venérea, al igual que la lepra, es un castigo divino.

Todavía más, en el primer tomo de Historia de la sexualidad, Foucault arguye que la sexualidad era algo que se mantuvo callado luego del siglo XVII en la Inglaterra victoriana:

Todavía a comienzos del siglo XVII era moneda corriente, se dice, cierta franqueza. Las prácticas no buscaban el secreto; las palabras se decían sin excesiva reticencia, y las cosas sin demasiado disfraz; se tenía una tolerante familiaridad con lo ilícito. Los códigos de lo grosero, de lo obsceno y de lo indecente, si se los compara con los del siglo XIX, eran muy laxos. Gestos directos, discursos sin vergüenza, trasgresiones visibles, anatomías exhibidas y fácilmente entremezcladas, niños desvergonzados vagabundeando sin molestia ni escándalo entre las risas de los adultos: los cuerpos se pavoneaban.

A ese día luminoso habría seguido un rápido crepúsculo hasta llegar a las noches monótonas de la burguesía victoriana. Entonces la sexualidad es cuidadosamente encerrada. Se muda. La familia conyugal la confisca. Y la absorbe por entero en la seriedad de la función reproductora. En torno al sexo, silencio. Dicta la ley la pareja legítima y procreadora. Se impone como modelo, hace valer la norma, detenta la verdad, retiene el derecho de hablar — reservándose el principio del secreto. Tanto en el espacio social como en el corazón de cada hogar existe un único lugar de sexualidad reconocida, utilitaria y fecunda: la alcoba de los padres. El resto no tiene más que esfumarse; la conveniencia de las actitudes esquiva los cuerpos, la decencia de las palabras blanquea los discursos. Y el estéril, si insiste y se muestra demasiado, vira a lo anormal: recibirá la condición de tal y deberá pagar las correspondientes sanciones. ${ }^{32}$

Al llegar a este punto podemos observar la parte condenatoria sobre la sexualidad en el comienzo de la época victoriana, secuela de una época donde la sexualidad no era tan reprimida.

\footnotetext{
${ }^{31}$ Foucault, Michel (n.d.). Historia de la locura en la época clásica. Recuperado de http://foucault.pbworks.com/f/locura1.pdf

${ }^{32}$ Foucault, Michel (n.d.). Historia de la sexualidad. Recuperado de http://www.uruguaypiensa.org.uy/imgnoticias/681.pdf
} 


\section{LA VISIÓN DEL OTRO: HOMOSEXUALES INDOANTILLANOS EN LA ÉPOCA DE LA CONQUISTA}

Se puede divisar la importancia de la reproducción en la sociedad europea. Pero esto no se queda ahí. Existieron lugares donde sí se podía romper un poco ese silencio:

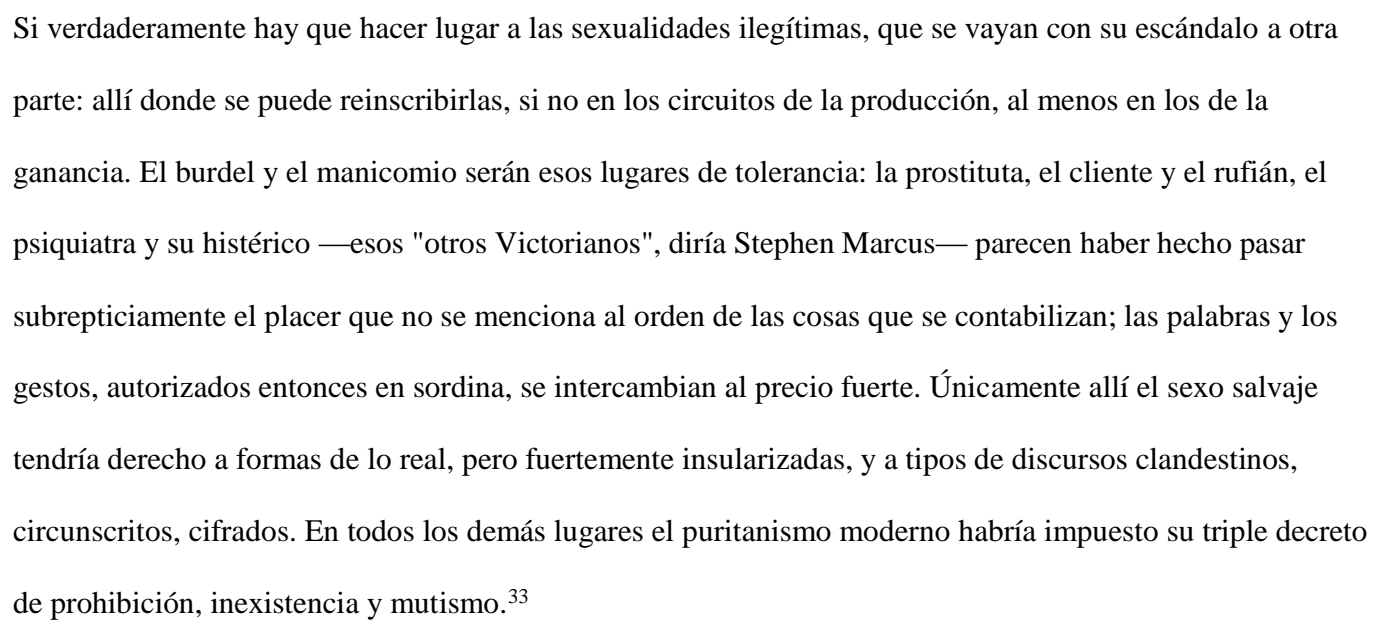

Consecuentemente, no se puede tildar a la sexualidad del medioevo como una que era siempre condenatoria: al contrario, aunque existió mucho silencio al respecto — como se podía sentir en la cita de Boswell—, habían lugares para mitigar ese silencio. Empero, las últimas dos citas Foucault se refiere a la época victoriana, viz. se está refiriendo a los británicos: no todos los países europeos eran así — como lo señala en la última oración. La cuestión del silencio y los lugares especiales hacen paralelismo con los sucesos en La Celestina ${ }^{34}$.

Esta represión puede explicar parte de la violencia de los españoles cuando venían a conquistar. En el primer viaje ellos viajaron durante seis meses. ¿Cómo hacían para satisfacer sus necesidades sexuales? ¿Habrán cometido actos de sodomía? Estas preguntas retóricas, aunque no tiene fácil respuesta, es importante planteárselas. Para retomar el asunto de la violencia de los españoles, la cita a continuación muestra los extremos a los que se pueden llegar:

Mientras estaba en la barca, hice cautiva a una hermosísima mujer caribe, que el susodicho Almirante me regaló, y después que la hube llevado a mi camarote, y estando ella desnuda según es su costumbre, sentí

\footnotetext{
33 Ibid.

${ }^{34}$ Fue una tragicomedia escrita por Fernando de Rojas que relata la historia de amor entre Calisto y Melibea y la intromisión de la Celestina para unir a los dos enamorados.

De Rojas, Fernando (n.d.). La Celestina. Recuperado de http://biblio3.url.edu.gt/Libros/2011/la_celes.pdf
} 


\section{LA VISIÓN DEL OTRO: HOMOSEXUALES INDOANTILLANOS EN LA ÉPOCA DE LA CONQUISTA}

deseos de holgar con ella. Quise cumplir mi deseo pero ella no lo consintió y me dio tal trato con sus uñas que hubiera preferido no haber empezado nunca. Pero al ver esto (y para contártelo todo hasta el final), tomé una cuerda y le di de azotes, después de los cuales echó grandes gritos, tales que no hubieras podido creer tus oídos. Finalmente llegamos a estar tan de acuerdo que puedo decirte que parecía haber sido criada en una escuela de putas. ${ }^{35}$

\section{Europa llega al Nuevo Mundo}

Cristóbal Colón llega por primera vez a América; suceden las primeras observaciones sobre las prácticas homosexuales en los indígenas. Él llega sesgado con sus ideas de cíclopes, sirenas, la Tierra en forma de pera y la malinterpretación del lenguaje indígena ${ }^{36}$. La hermenéutica de Cristóbal Colón es muy bien explicada por Todorov: “Así, pues, quizás no sea casual el que hayamos encontrado tres móviles para la conquista: el primero humano (la riqueza), el segundo divino, y el tercero relacionado con el disfrute de la naturaleza" ${ }^{\text {37. Esos }}$ móviles, según explica Todorov, hacen que la conquista de América sea, ante los ojos de Colón, una situación inevitable: “Colón mismo, después de los hechos, atribuye su descubrimiento a ese saber a priori, que identifica con la voluntad divina y con las profecías (a las que, de hecho, recurre mucho en ese sentido)"38. Con esto en mente, ¿por qué se han tomado las crónicas de indias como si fuesen sacrosantas escrituras?

Según las diferentes crónicas, los europeos se encuentran a dos grupos primordiales de indígenas en el caribe: los indios taínos y los indios caribes. De los primeros se decía que eran pacíficos; de los segundos se dicen que eran antropófagos, sodomitas, y enemigos de los cristianos.

\footnotetext{
35 Tzvetan Todorov (1989). La conquista de América. Siglo Veintiuno Editores, pp. 56.

${ }^{36}$ Ibid., pp 23, Colón hermeneuta.

${ }^{37}$ Ibid., pp. 23-34.

${ }^{38}$ Ibid., pp. 31.
} 


\section{LA VISIÓN DEL OTRO: HOMOSEXUALES INDOANTILLANOS EN LA ÉPOCA DE LA CONQUISTA}

Además, en una visita a la clase CISO 3265 LD0 del semestre agosto-diciembre 2013,

Dr. José Rodríguez puntualizo que los españoles entendieron a los indígenas en tres grupos principales: los bárbaros, los sumisos y los caribes.

Los del primer conjunto era un grupo de indígenas que tenían características salvajes. Pese a ello, se podían domesticar hasta cierto grado. Los del segundo conjunto, los sumisos, eran indígenas que se caracterizaban por ser completamente domesticables. Los del tercer conjunto eran completamente violentos y no se podían domesticar de ninguna manera: su naturaleza diabólica era inmanejable.

El dato anterior sobre los caribes es curioso. Tomando el argumento de $\mathrm{Bosh}^{39}$, los caribes eran quienes trazaban la frontera entre un continente vacío — desde el punto de vista de los europeos - y el imperio español.

\section{Sexualidad indígena}

Los indígenas tenían una epistemología diferente respecto a la sexualidad europea. Por ejemplo, un menor podía saber la vida sexual de todas las personas de su tribu ${ }^{40}$. Esto se diferencia grandemente del paradigma europeo que hemos heredado hasta la contemporaneidad. Dicho de otra forma, hay que imaginar la sexualidad indígena como un fenómeno muy diferente a las costumbres sexuales europeas.

Se ha tildado al indígena de ser apático con la cuestión erótica, por lo que

\footnotetext{
${ }^{39}$ Bosh, Juan (2009). De Cristóbal Colón a Fidel Castro:el Caribe como frontera imperial. México, H. Cámara de Diputados, LX Legislatura. Recuperado de http://biblioteca.diputados.gob.mx/janium/bv/ce/scpd/LX/cris_colon.pdf

${ }^{40}$ Anónimo (n.d.).Sexualidad precolombina: fuerza sagrada dignificadora de las capacidades humanas y no necesariamente reproductiva. Recuperado de http://www.jornada.unam.mx/2005/01/03/pdf/pdf_paginas/P3Tri77.pdf
} 


\section{LA VISIÓN DEL OTRO: HOMOSEXUALES INDOANTILLANOS EN LA ÉPOCA DE LA CONQUISTA}

hay en la forma taina, en su más ligera manifestación, una expresión solemne y dramática. El escultor taino no conoció lo sensual, pero si lo sexual. Su forma escultórica excluye lo placentero. Su arte estuvo al servicio de la religión, del Estado o de la magia. ${ }^{41}$

Entiéndase bien: se puede interpretar que la cuestión sexual era algo jubiloso que concierne a los grandes misterios de la humanidad y, por consiguiente, necesaria para explicaciones supersticiosas. Suro sigue abundando en el asunto:

\footnotetext{
Hay una concepción pura en los amuletos tainos. En ellos no aparece la mezcla. Recordamos que casi siempre la mentalidad indígena americana mezclaba ideas lógicas y no lógicas. En ninguno de los amuletos mostrados se encontrará la mezcla de la bestia y el hombre, como sucede como el majador ritual. El motivo, ya sea zoomorfo o antropomorfo, es usado en su estado puro. Sin embargo, repiten hasta lo incalculable la posición en cuclillas, o acurrucada. No olvidemos que los tainos enterraban a sus muertos en esa posición, lo que nos hace figurar que estos amuletos representaban el espíritu del muerto mezclado con su imaginación totémica. Obsérvese que todos los amuletos antropomorfos conservan esa actitud que es la del orante de todas las religiones del mundo. Esto viene a confirmar, en efecto que todo el arte taino estuvo movido por ideas religiosas y mágicas, con una propensión muy marcada a acentuar las estímulos sexuales en una forma casi siempre simbólica. ${ }^{42}$
}

La cita anterior insiste en el asunto de encontrar explicaciones religiosas a los fenómenos que acontecen en la naturaleza. Recordemos que la religión indígena era la ciencia que tenían los indígenas para explicar su entorno. Por eso se entiende que la sexualidad formaba parte de esa explicación simbólica y no una ejemplificación erótica. En las siguientes imágenes se puede observar el antierotismo de los indígenas.

\footnotetext{
${ }^{41}$ Suro, Darío (10/diciembre/ 1969). El arte taíno. América, No.278, pp. 65-68. Recuperado de http://desdelavegardubsolis.blogspot.com/2012/08/el-arte-taino.html ${ }^{4}$ Ibid.
} 
LA VISIÓN DEL OTRO: HOMOSEXUALES INDOANTILLANOS EN LA ÉPOCA DE LA CONQUISTA

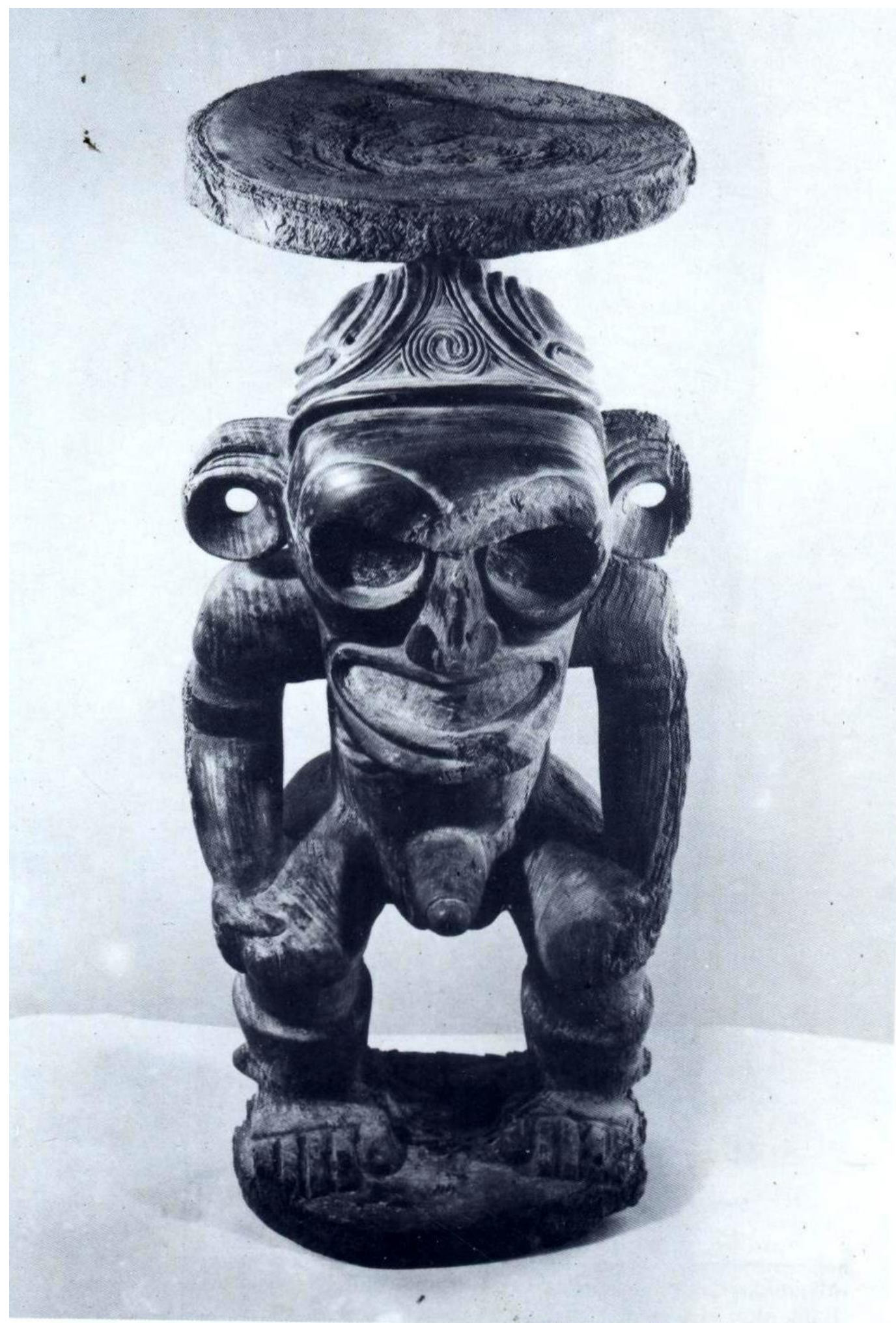

Ilustración 2: Cemí indígena. ${ }^{43}$

43 Ibid. 
LA VISIÓN DEL OTRO: HOMOSEXUALES INDOANTILLANOS EN LA ÉPOCA DE LA CONQUISTA

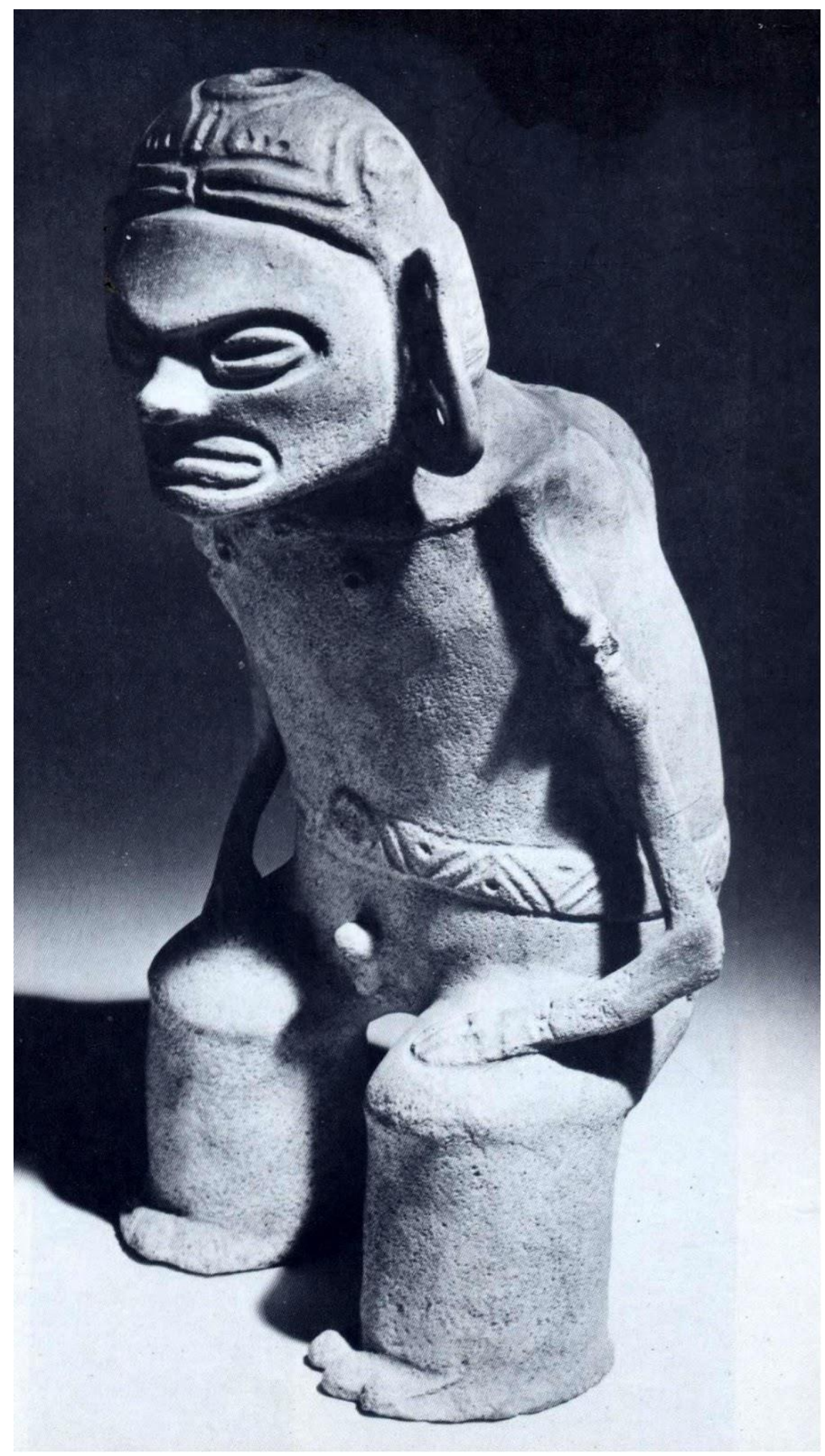

Ilustración 3: Cemí indígena. 44

${ }^{4}$ Ibid. 
LA VISIÓN DEL OTRO: HOMOSEXUALES INDOANTILLANOS EN LA ÉPOCA DE LA CONQUISTA

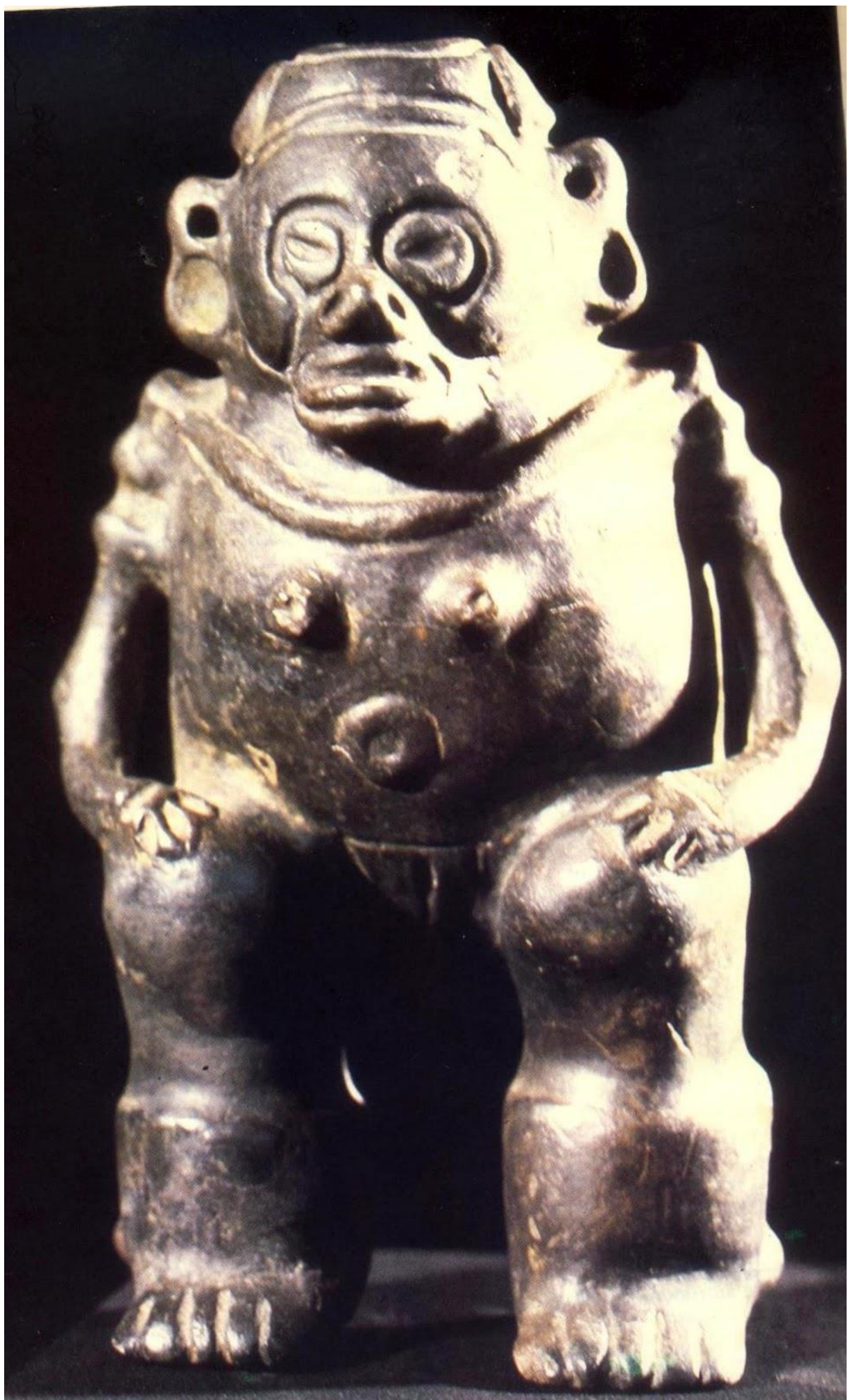

Ilustración 4: Cemí indígena. ${ }^{45}$ 


\section{LA VISIÓN DEL OTRO: HOMOSEXUALES INDOANTILLANOS EN LA ÉPOCA DE LA CONQUISTA}

Por otro lado, Fray Ramón Pané fue el primer cronista en relatar las supuestas creencias

de los indígenas. En su breve obra se puede atisbar el origen de la mujer ${ }^{46}$. He aquí el relato:

Dicen que un día fueron a lavarse los hombres, y estando en el agua, llovía mucho, y que estaban muy deseosos de tener mujeres; y que muchas veces, cuando llovía, habían ido a buscar las huellas de sus mujeres; mas no pudieron encontrar alguna nueva de ellas. Pero aquel día, lavándose, dicen que vieron caer de algunos árboles, bajándose por entre las ramas, una cierta forma de personas, que no eran hombres ni mujeres, ni tenían sexo de varón ni de hembra, las cuales fueron a cogerlas; Por lo cual llamaron a dos o tres hombres por mandato de su cacique, puesto que ellos no podían cogerlas, para que viesen cuántas eran y buscasen para cada una un hombre que fuese caracaracol, porque tenían las manos ásperas, y que así estrechamente las sujetasen. Dijeron al cacique que eran cuatro; y así llevaron cuatro hombres, que eran caracaracoles. El cual caracaracol es una enfermedad como sarna, que hace al cuerpo muy áspero. Después que las hubieron cogido, tuvieron consejo sobre cómo podían hacer que fuesen mujeres, puesto que no tenían sexo de varón ni de hembra.

[...] Buscaron un pájaro que se llama inriri, antiguamente llamado inriri cahubabayeal, el cual agujerea los árboles, y en nuestra lengua llámase pico. E igualmente tomaron a aquellas mujeres sin sexo de varón ni de hembra, y les ataron los pies y las manos, y trajeron el pájaro mencionado, y se lo ataron al cuerpo. Y éste, creyendo que eran maderos, comenzó la obra que acostumbra, picando y agujereando en el lugar donde ordinariamente suele estar el sexo de las mujeres. Y de este modo dicen los indios que tuvieron mujeres, según cuentan los más viejos. Puesto que escribí de prisa, y no tenía papel bastante, no pude poner en su lugar lo que por error trasladé a otro; pero con todo y eso, no he errado, porque ellos lo creen todo tal como lo he escrito. 47

\footnotetext{
${ }^{46}$ Pané, Ramón (n.d.). Relación acerca de las antigüedades de los indios. Siglo Veintiuno Editores. Recuperado de http://inabima.gob.do/descargas/bibliotecaFAIL/Autores\%20Dominicanos/Fray\%20Ramon\%20Pane/Fray\%20Ramo n\%20Pane \%20-\%20Relacion\%20acerca\%20de\%201as\%20antiguedades\%20de\%20los\%20indios.pdf

${ }^{47}$ Ibid., pp. 26-28.
} 


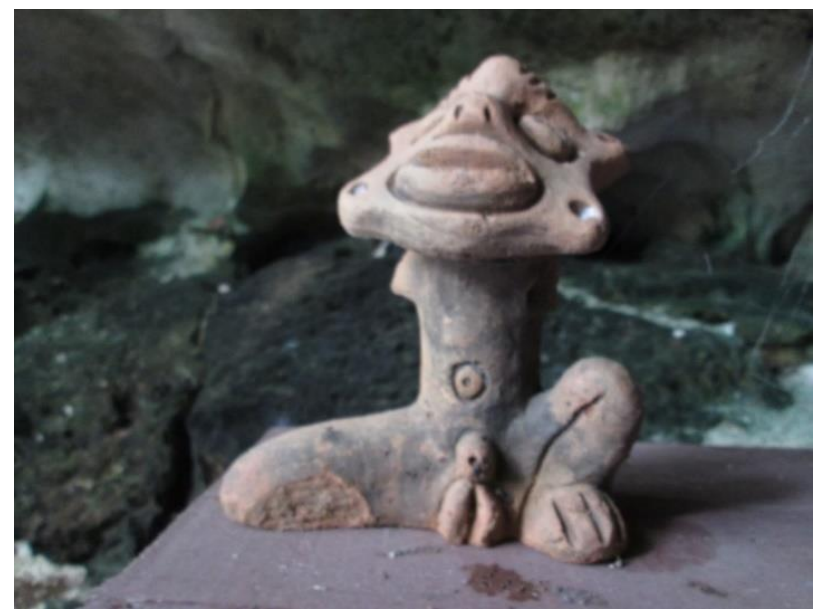

Ilustración Error! Reference source not found.: Escultura taína. ${ }^{48}$

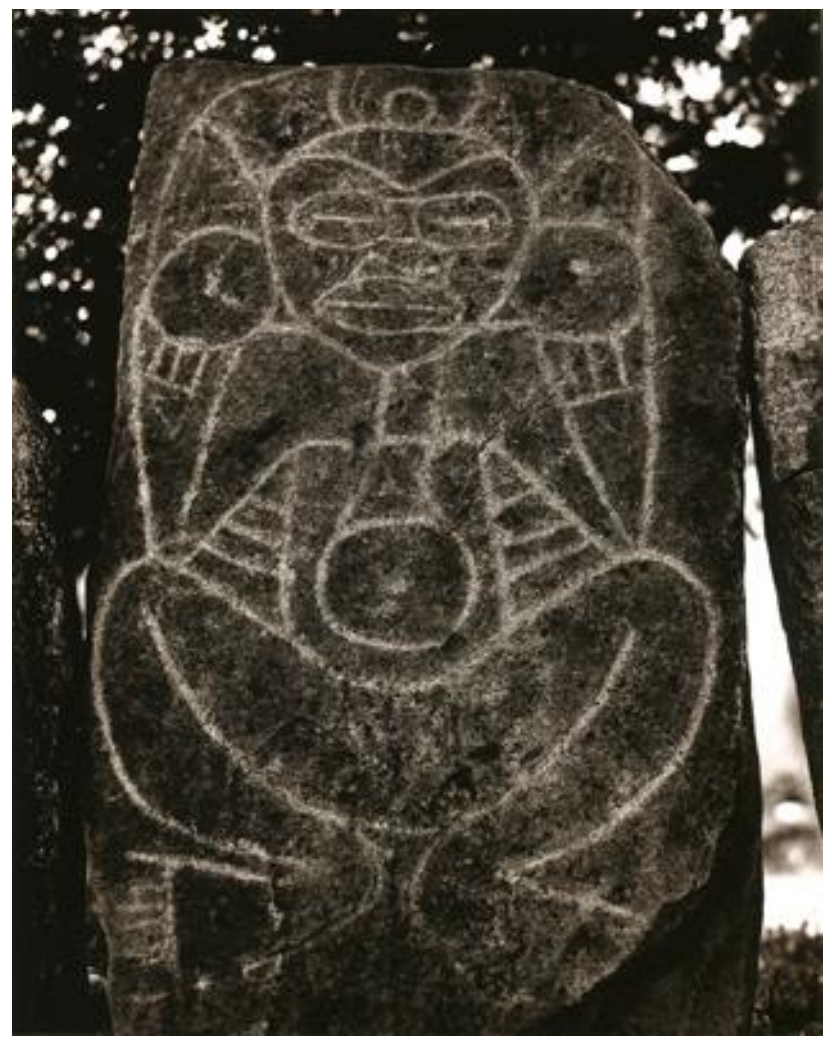

Ilustración 5: Mujer de Caguana. ${ }^{49}$

${ }^{48}$ Piñerúa Monasterio, Félix (8/julio/2013). Cultura Taína- Sistema de Creencias Taína. Antropología y Ecología UPEL. Recuperado de http://antropologiayecologiaupel.blogspot.com/2013/07/cultura-taina-sistema-de-creenciastaina.html

${ }^{49}$ Méndez Caratini, Héctor (n.d.). Petroglifos de Boriquén, 1975-1995. Héctor Méndez Caratini: vídeos y fotografías de Puerto Rico y Latinoamérica. Recuperado de http://hectormendezcaratini.com/2013/fotografias-enblanco-negro/petroglifos-1975-1995/ 


\section{LA VISIÓN DEL OTRO: HOMOSEXUALES INDOANTILLANOS EN LA ÉPOCA DE LA CONQUISTA}

A mi juicio, Pané documentó algunos mitos indígenas, pero es inexacto: da por sentado que los indígenas supuestamente creen lo que él escribió. Pero, dejando a un lado la cuestión del yerro, se puede ver que la cuestión sexual no contiene erotismo. Asimismo, se puede comparar con el relato de Génesis en la Biblia: dicho en otros términos, los dos relatos contienen la querencia del hombre por alguna compañera. En el relato indígena, como las mujeres habían desparecido $^{50}$, la problemática se resolvió creando a las compañeras. Lo mismo sucede en el relato de Lilith y Adán ${ }^{51}$, dado que el hombre quiso una mujer que se pudiese someter, así que Dios creó a Eva para que le sirviese de compañía.

Por otro lado, Georges Bataille, en su libro Las lágrimas de Eros, argumenta que en diferentes épocas existió una relación entre el erotismo y la muerte —inclusive en la prehistoria. El europeo — especialmente el español— es quien tilda de "diabólico" a toda costumbre diferente al pudoroso amor cristiano ${ }^{52}$. El erotismo se visualiza desde lejos, a la distancia, con el máximo recato: todo lo que esté fuera de la norma del matrimonio se considera nocivo, pecaminoso.

Para simbolizar el pecado, los artistas de la Edad Media pintaban desnudas a las personas:

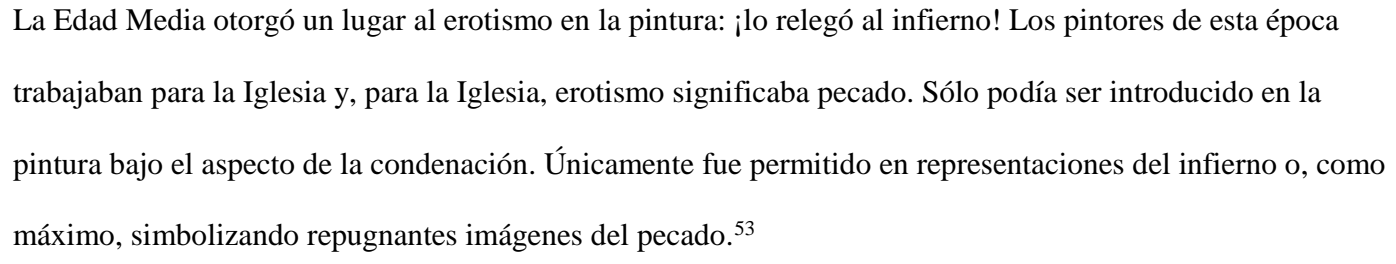

\footnotetext{
${ }^{50}$ Pané, Ramón (n.d.). Relación acerca de las antigüedades de los indios. Siglo Veintiuno Editores, pp. 23. Recuperado de http://inabima.gob.do/descargas/bibliotecaFAIL/Autores\%20Dominicanos/Fray\%20Ramon\%20Pane/Fray\%20Ramo n\%20Pane\%20-\%20Relacion\%20acerca\%20de\%20las\%20antiguedades\%20de\%201os\%20indios.pdf

${ }^{51}$ Lilith (n.d.). Wikipedia. Recuperado de http://es.wikipedia.org/wiki/Lilit

52 Bataille, Georges (1981). Las lágrimas de Eros. Barcelona, España: Tusquets Editores, pp. 37.

53 Ibid., pp. 92.
} 


\section{LA VISIÓN DEL OTRO: HOMOSEXUALES INDOANTILLANOS EN LA ÉPOCA DE LA CONQUISTA}

La desnudez, en el acto erótico, se puede ver como el preámbulo para sentir la "petite

mort («pequeña muerte») ${ }^{\natural 54}$, pero en el ámbito cristiano es una perversión si se comete fuera del matrimonio. Así que, en el argumento de Bataille, no podemos separar la muerte del erotismo:

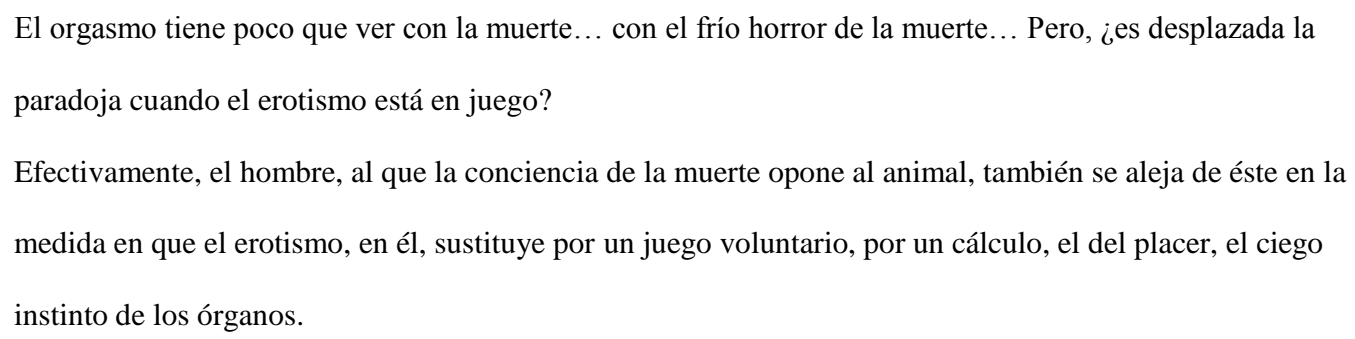

En algunas obras como Justine ${ }^{55}$, Filosofía en el tocador ${ }^{56}$, La Celestina y Romeo y Julieta $^{57}$ se puede observar también la imbricación erotismo-muerte. Más adelante retomaremos la cuestión del erotismo.

Es oportuno recalcar ahora que, aunque no se puede saber a ciencia cierta cómo era la sexualidad indígena, podemos vislumbrar lo que no era: no compartía una sexualidad enraizada en el matrimonio, sus esculturas carecían de erotismo y no eran europeos con unas ideas oblicuas sobre la sexualidad.

\section{"Traían por joyel un hombre sobre otro": lo que vio Gonzalo Fernández de Oviedo}

Como se ha mencionado en párrafos anteriores, la verdadera conquista comenzó con la imposición de mores cristianos, tanto de los explotadores de los indios como de los defensores — la idea de la evangelización es una excusa para imponer mores. Gonzalo Fernández de Oviedo hace una crítica visceral hacia los indígenas en su obra magna Historia general y natural de las

\footnotetext{
${ }^{54}$ Ibíd., pp. 58, la petite mort es el orgasmo.

${ }^{55}$ De Sade, Marqués (n.d.). Justine. Recuperado de http://seronoser.free.fr/sade/1788\%20Justine.pdf

${ }^{56}$ De Sade, Marqués (n.d.). Filosofía en el tocador. Recuperado de http://losdependientes.com.ar/uploads/sucj31sdk.pdf

${ }^{57}$ Romeo y Julieta fue una tragedia entre dos jóvenes que deciden casarse a escondidas pero todo resulta en el suicidio.

Shakespeare, William (n.d.). Romeo y Julieta. Recuperado de

http://www.edu.mec.gub.uy/biblioteca_digital/libros/s/Shakespeare\%20-\%20Romeo\%20y\%20Julieta.pdf
} 


\section{LA VISIÓN DEL OTRO: HOMOSEXUALES INDOANTILLANOS EN LA ÉPOCA DE LA CONQUISTA}

indias. Ese escrito es un excelente aliado a la hora de interpretar la sexualidad indígena, especialmente en el Libro V, capítulo III, porque su crítica al otro, o sea, al indígena, es una llena de estereotipos alimentados por sus creencias cristianas: su crítica del indígena es una manera de mostrar que ellos no son el ejemplo cristiano. Es obvio que Oviedo no tiene el carisma de Fray

Bartolomé de las Casas para aminorar el sufrimiento de los indios. Ecce signum:

\footnotetext{
Así que, lo que he dicho desta gente en esta isla y las comarcanas, es muy público, y aun en la Tierra Firme, donde muchos destos indios e indias eran sodomitas, e se sabe que allá lo son muchos dellos. Y ved en qué grado se prescian de tal culpa, que, como suelen otras gentes ponerse algunas joyas de oro y de presciosas piedras al cuello, así, en algunas partes destas Indias; traían por joyel un hombre sobre otro [ilustración 1], en aquel diabólico e nefando acto de Sodoma, hechos de oro de relieve. Yo ví uno destos joyeles del diablo que pesaba veinte pesos de oro, hueco, vaciado e bien labrado, que se hobo en el puerto de Sancta Marta, en la costa de Tierra Firme, año de mil e quinientos e catorce, cuando allí tocó el armada quel Rey Católico envió con Pedrarias Dávila, su capitán general, a Castilla del Oro. E cómo se trujo a montón el oro que allí se tomó, e lo llevaron después a fundir ante mí, como official real veedor de las fundiciones del oro, yo lo quebré con un martillo e lo machaqué por mis manos sobre un tas o yunque en la casa de la fundición, en la cibdad del Darién. $^{58}$
}

\footnotetext{
${ }^{58}$ Fernández de Oviedo, Gonzalo (n.d.) Historia general y natural de las indias. Pp. 134. Recuperado de http://www.biblioteca-antologica.org/wp-content/uploads/2009/09/FERN\%C3\%81NDEZ-DE-OVIEDO-Historiageneral-y-natural-I.pdf
} 


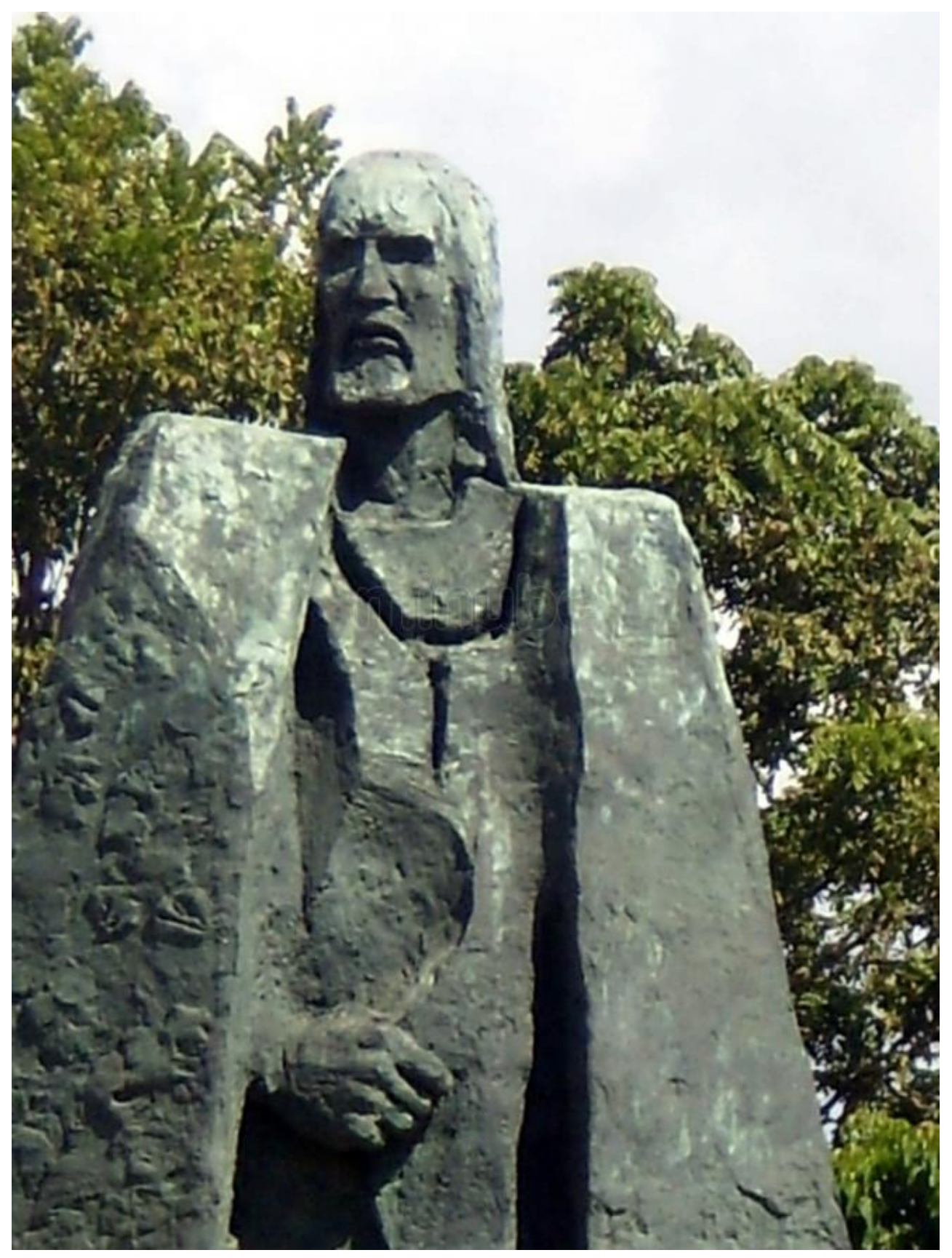

Ilustración 6: Monumento a Gonzalo Fernández de Oviedo en Fortaleza Ozama, Santo Domingo, República Dominicana. ${ }^{59}$

Es muy importante la primera oración porque puntualiza un dato importante: la gente sabía que los indígenas hacían prácticas homosexuales. Al referirse a ellos como "sodomitas" los

${ }^{59}$ López Nieves, Léster (6/mayo/2013). Puertorriqueños sodomitas, vagos y parejeros. Garita del Diablo. Recuperado de http://garitadeldiablo.wordpress.com/2013/05/06/puertorriquenos-sodomitas-vagos-y-parejeros/ 


\title{
LA VISIÓN DEL OTRO: HOMOSEXUALES INDOANTILLANOS EN LA ÉPOCA DE LA CONQUISTA
}

convierte en herejes, propiciando la posibilidad de someterlos; el acto de sodomía era una aberración equivalente a comer hombres o ser enemigos de los cristianos. Pero ahí no se queda la impresión de Fernández de Oviedo:

\begin{abstract}
Así que, ved si quien de tales joyas se prescia e compone su persona, si usará de tal maldad en tierra donde tales arreos traen, o si se debe tener por rosa nueva entre indios: antes por cosa muy usada e ordinaria e común a ellos. Y así, habés de sabes que el que dellos es paciente o toma cargo de ser mujer en aquel bestial e descomulgado acto, le dan luego oficio de mujer, e trae naguas como mujer. ${ }^{60}$
\end{abstract}

Se puede deducir claramente que Oviedo percibe a la mujer como algo inferior. El acto de feminizar al hombre — al igual que en la Biblia ${ }^{61}$ — es un acto vergonzoso para el feminizado. Se puede decir, aunque no con toda seguridad, que los indígenas tenían equidad para las personas homosexuales, puesto que los indígenas que usaban naguas estaban casados, y las mujeres eran las que comúnmente utilizaban naguas ${ }^{62}$, o como dice en el Diccionario taíno ilustrado: "naguas. Especie de faldas o delantales que usaban las mujeres casadas o las que tenían pretendientes; desde la cintura hasta la rodilla o un poco más abajo. Preparadas de algodón tejido a veces teñido"63. Empero, no pasaba lo mismo con los hombres. Como se menciona en la cita de Oviedo, los hombres que se veían en actos homosexuales eran los únicos a los que se les ponían naguas. Es decir, en el mundo indígena las parejas homosexuales podían tener algún tipo de unión parecida al matrimonio. Como dato curioso, en el Diccionario taíno ilustrado se encuentra el siguiente significado: "naguacokios. Hombres vestidos con naguas"

\footnotetext{
${ }^{60}$ Fernández de Oviedo, Gonzalo (n.d.) Historia general y natural de las indias, pp. 134. Recuperado de http://www.biblioteca-antologica.org/wp-content/uploads/2009/09/FERN\%C3\%81NDEZ-DE-OVIEDO-Historiageneral-y-natural-I.pdf

61 Ver 16I.

${ }^{62}$ Anónimo (n.d.). Desde Colón hasta la invasión norteamericana. Puerto Rico: "preciosa por ser un encanto por ser un edén”. Recuperado de http://www.prfrogui.com/geocities/indios.html

${ }^{63}$ Miner Solá, Edwin (2008). Diccionario taíno ilustrado. Ediciones Servilibros, pp. 31.

64 Ibid.
} 


\section{LA VISIÓN DEL OTRO: HOMOSEXUALES INDOANTILLANOS EN LA ÉPOCA DE LA CONQUISTA}

Como se puede observar, Gonzalo Fernández de Oviedo observó una serie de sucesos fantásticos. Me he dedicado a mostrar los que son de mayor interés para la investigación. Por ende, la siguiente cita es importante para entender las ofuscaciones europeas:

\footnotetext{
Para un agente comercial en una empresa de muy alta prioridad de Estado, la exhuberancia tropical con sus comunes configuraciones poblacionales no podían desviarles de lo que siempre fue su objetivo geográfico principal: los centros urbanos del Oriente, la corte del Gran Khan. ${ }^{65}$

No obstante, para hacer el paralelismo con la descripción de Oviedo respecto a la
} popularidad de los actos sodomitas en los indios caribes, cito lo siguiente sobre las expectativas de búsqueda en el Nuevo Mundo: "estas descripciones de tipos monstruosos no eran una novedad a los oídos del europeo de la época"66. Además, “Los términos ‘caníbales' y 'oro' se habían vuelto sinónimos"67. Hicieron hasta un "viaje de la 'corroboración"”68. Por consiguiente, estas cuestiones sobre lo extraordinario de los relatos de los caribes —que son parecidos a las descripciones sobre amazonas, cíclopes y sirenas — nos llevan al siguiente subtema.

\section{El discurso homofóbico ${ }^{69}$ como catalizador de la conquista}

Victor Wahlström, en su tesina Lo fantástico y lo literario en las Crónicas de Indias, arguye que

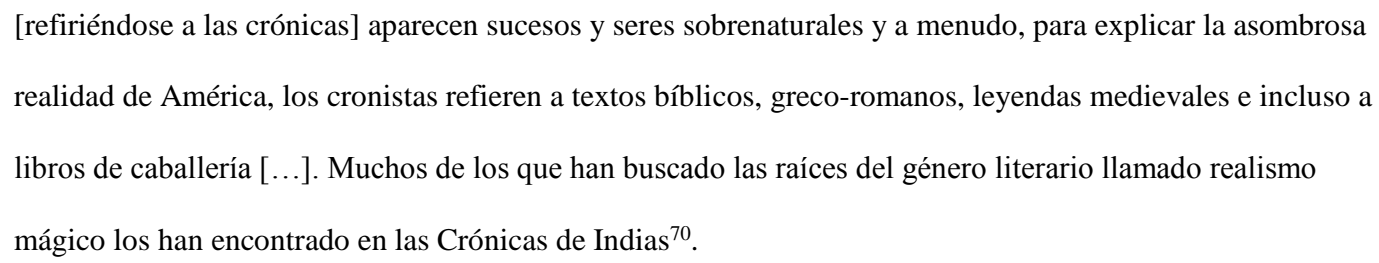

${ }^{65}$ Sued Badillo, Jalil (1978). Los caribes: realidad o fábula. Río Piedras, P.R.: Editorial Santillana, pp. 33.

${ }^{66}$ Ibid., pp. 36.

${ }^{67}$ Ibid., pp. 38.

${ }^{68}$ Ibid., pp. 41.

${ }^{69}$ Según el Diccionario de la Real Academia Española, homofobia es la "aversión obsesiva hacia las personas homosexuales". Recuperado de http://buscon.rae.es/drae/srv/search?val=homofobia

${ }^{70}$ Wahlström, Victor (n.d.) Lo fantástico y lo literario en las Crónicas de Indias. Recuperado de http://lup.lub.lu.se/luur/download?func=downloadFile\&recordOId=1485594\&fileOId=1497036 


\section{LA VISIÓN DEL OTRO: HOMOSEXUALES INDOANTILLANOS EN LA ÉPOCA DE LA CONQUISTA}

Ergo, la crítica de que los caribes eran sodomitas, antropófagos y enemigos de los cristianos puede ser un artificio europeo - y lo mismo se podría decir de la existencia de los indios caribes. Jalil Sued Badillo es una de las personas que propone la inexistencia de los indios caribes en su libro Caribes: realidad o fábula. Él propone que los dos grupos indígenas en el Caribe fueron en realidad un grupo homogéneo ${ }^{71}$. En este trabajo no me adentraré en el debate sobre la existencia de los indios caribes, pero sí propondré que la manera en que los describían era para demonizarlos. Examinemos brevemente este problema: si existieron, eran individuos homosexuales además de antropófagos; si no existieron, la homosexualidad fue una de las características utilizadas para crear la bien confabulada mitología de los indios caribes.

En la siguiente cita del libro Historia general y natural de las indias, libro XVII, capítulo

XVII, Oviedo sigue con sus descripciones sobre la sodomía:

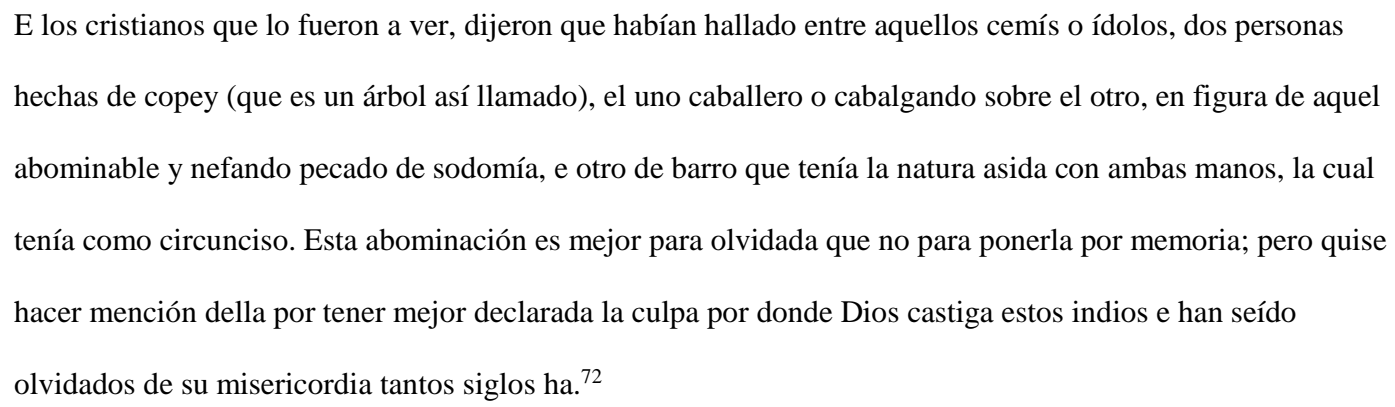

Claramente se puede ver una crítica a esos hombres endemoniados. Para Oviedo esa

escena fue imposible de olvidar, dado que era el mejor ejemplo para relatar a los españoles lo abominables y primitivos que eran los indígenas. Sin embargo, no eran cualquier tipo de hombres. La descripción del hombre masturbándose es paralela a describir a un judío, ya que los judíos también eran circuncisos. ¿Estará Oviedo sesgado por las historias fantásticas de monstruos, cíclopes, sirenas y amazonas?

\footnotetext{
${ }^{71}$ Sued Badillo, Jalil (1978). Los caribes: realidad o fábula. Río Piedras, P.R.: Editorial Santillana, pp. 1.

${ }^{72}$ Fernández de Oviedo, Gonzalo (n.d.) Historia general y natural de las indias, pp. 518. Obtenido de http://www.biblioteca-antologica.org/wp-content/uploads/2009/09/FERN\%C3\%81NDEZ-DE-OVIEDO-Historiageneral-y-natural-I.pdf
} 


\title{
LA VISIÓN DEL OTRO: HOMOSEXUALES INDOANTILLANOS EN LA ÉPOCA DE LA CONQUISTA
}

Jalil Sued Badillo argumenta lo siguiente: "Los españoles acusaron de canibalismo, de sodomía, de idolatría o de incapacidad política a los aborígenes haciendo uso de clasificaciones indígenas que pertenecían a dimensiones claramente simbólicas o metafísicas" ${ }^{\text {,73 }}$. Al igual que otras citas de Badillo, se puede notar que los españoles venían con un paradigma cristiano. Venían para evangelizar; venían para conquistar; venían para civilizar.

Retomando el argumento de Georges Bataille, en el hombre civilizado se puede ver, en el texto de Gonzalo Fernández de Oviedo, una imbricación entre el erotismo y la muerte. En los textos Las lágrimas de Eros, Erotismo y La literatura y el mal, Bataille explica la relación de Marqués de Sade con la cuestión de la muerte y lo erótico, dándole un matiz de perversión. Claro está, Sade perteneció a una época donde imperaba la ilustración —en otras palabras, las ideas de Sade surgieron luego de la Edad Media; Sade fue un pre-romántico. De todas maneras, la perversión que es vista en el otro por parte de Oviedo imbrica la antropofagia y la sodomía, una reverberación de la dicotomía muerte y erotismo demarcado desde una perspectiva medieval.

\section{Conclusiones}

\author{
"En los Desiertos del Oeste perduran despedazadas Ruinas del Mapa, habitadas \\ por Animales y por Mendigos". \\ — Jorge Luis Borges, Del rigor de la ciencia. \\ "Le vestían de mujer le enseñaban artes, le buscaban marido y le casaban". \\ —Fray Bartolomé de las Casas, Historia de las Indias.
}

Hasta aquí el lector ha tenido un atisbo del universo indígena que le he podido presentar: ha podido observar el modus operandi del hombre europeo y su exégesis del homosexualismo indígena. Mi telescopio no tendrá la mejor resolución y, al igual que le telescopio de Galileo

\footnotetext{
${ }^{73}$ Sued Badillo, Jalil (1978). Los caribes: realidad o fábula. Río Piedras, P.R.: Editorial Santillana, pp. 67.
} 


\section{LA VISIÓN DEL OTRO: HOMOSEXUALES INDOANTILLANOS EN LA ÉPOCA DE LA CONQUISTA}

Galilei observando a Saturno, se ve borroso. Pese a ello lo hemos observado con el rigor necesario, aunque quedan por definir sus contornos desdibujados.

Después de todo, parece que nuestra epistemología para entender lo que conocemos como homosexualidad a veces nos falla y parece repetir las críticas del pasado. Para ilustrar mejor, esto se puede ver en el caso de los homosexuales en Uganda, cuyo presidente firmó una ley para condenar a los homosexuales a cadena perpetua ${ }^{74}$ : esto crea disturbios respecto a la prevención del SIDA ${ }^{75}$ y cuestiones políticas ${ }^{76}$. Por lo tanto, no nos hemos librado mucho de las monomanías atávicas.

Al llegar a este punto quedan varias preguntas por contestar después de incursionar en este viaje para entender las prácticas sexuales y homosexuales indígenas: ¿cuál es la familia tradicional: la que llegó impuesta por la conquista o la que estaba aquí desde hace más de 6,000 años? ¿Quiénes tenían mejor moral? ¿Existieron los caribes y con ellos sus actos homosexuales o fueron inventados e envilecidos con actos de sodomía y antropofagia? Estas preguntas retóricas, aunque absurdas, trazan el decurso de nuestra historia como antillanos: un supuesto descubrimiento; un accidente produjo lo que conocemos hoy. Los prejuicios europeos y el libertinaje indígena se unieron para crear una desestabilización, un caos en el paradigma eurocentrado. Talis Est Vita.

\footnotetext{
${ }^{74}$ El presidente de Uganda firma la ley que condena a los homosexuales a cadena perpetua. El Mundo. Recuperado de http://www.elmundo.es/internacional/2014/02/24/530b419a22601d1e1c8b457f.html

${ }^{75}$ Loc. Cit.

${ }^{76}$ Uganda 'homosexuals' named in Red Pepper paper (25/ febrero/ 2014). BBC News: Africa. Recuperado de http://www.bbc.com/news/world-africa-26338941
} 
LA VISIÓN DEL OTRO: HOMOSEXUALES INDOANTILLANOS EN LA ÉPOCA DE LA CONQUISTA

\section{Referencias}

Anónimo (n.d.) Biblia Reina-Valera 1960. Recuperado de http://www.biblegateway.com/ Anónimo (n.d.). Castigos a homosexuales en España durante el Renacimiento.

Islaternura.com. Recuperado de http://www.islaternura.com/APLAYA/HOMOenHISTORIA/CastigosPARAhomosexualidad.ht $\mathrm{m}$

Anónimo (n.d.). Desde Colón hasta la invasión norteamericana. Puerto Rico: "preciosa por ser un encanto por ser un edén”. Recuperado de http://www.prfrogui.com/geocities/indios.html

Anónimo (n.d.). Homosexualidad en la Florencia renacentista. Islaternura.com.

Recuperado de http://www.islaternura.com/APLAYA/HOMOenHISTORIA/FLORENCIA/Antigua\%20Florenci a\%20Mayo\%202004.htm

Anónimo (27/noviembre/2009). La España musulmana (711-1492) .Recuperado de http://www.cdechamps-lycee-delacroix.fr/spip.php?article97

Anónimo (n.d.).Sexualidad precolombina: fuerza sagrada dignificadora de las capacidades humanas y no necesariamente reproductiva. Recuperado de http://www.jornada.unam.mx/2005/01/03/pdf/pdf_paginas/P3Tri77.pdf Bataille, Georges (1981). Las lágrimas de Eros. Barcelona, España: Tusquets Editores Bataille Georges (n.d.). Erotismo. Recuperado de http://www.artpaniagua.es/uploads/4/8/6/4/4864148/bataille_georges_-_el_erotismo_v1.1.pdf 
LA VISIÓN DEL OTRO: HOMOSEXUALES INDOANTILLANOS EN LA ÉPOCA DE LA CONQUISTA

Bataille, Georges (2000). La literatura y el mal. Recuperado de http://www.animalario.tv/PorcoArchivo/Biblioteca/18.\%20Georges\%20Bataille\%20$\% 20 \mathrm{La} \% 20$ literatura\%20y\%20el\%20mal.pdf

Bosh, Juan (2009). De Cristóbal Colón a Fidel Castro:el Caribe como frontera imperial. México, H. Cámara de Diputados, LX Legislatura. Recuperado de http://biblioteca.diputados.gob.mx/janium/bv/ce/scpd/LX/cris_colon.pdf

Boswell, John (n.d.). Cristianismo, tolerancia y homosexualidad. Recuperado de http://www.pridesites.com/sacerdotesgay/CTSYH/SG-CTSYH-07.htm

Cárdenas Ruiz, Manuel (1981). Crónicas Francesas de los Indios Caribes. Puerto Rico: Editorial Universidad de Puerto Rico.

Contranatural. Diccionario de la Real Academia Española (n.d.). Recuperado de Recuperado de http://buscon.rae.es/drae/srv/search?val=antinatural

Cruz Santos, Martín (n.d.). Aproximación comparativa a las crónicas españolas y francesas sobre las etnias del caribe, siglo XVI y XVII. Recuperado de http://www.academia.edu/3562008/Aproximacion_comparativa_a_las_cronicas_espanolas_y_fra ncesas_sobre_las_etnias_del_caribe_siglos_XVI_y_XVII

De Irala, Jokin (n.d.). Comprendiendo la homosexualidad. Recuperado de http://www.pfox.org/ebook_homosex_jokin_irala.pdf

De las Casas, Bartolomé (1875). Historia de las Indias, Madrid, España.

De Oviedo, Gonzalo F. (n.d.) Historia General y natural de las India. Recuperado de http://www.archive.org/stream/historiageneraly01 fern\#page/n7/mode/2up

De Rojas, Fernando (n.d.). La Celestina. Recuperado de http://biblio3.url.edu.gt/Libros/2011/la_celes.pdf 
LA VISIÓN DEL OTRO: HOMOSEXUALES INDOANTILLANOS EN LA ÉPOCA DE LA CONQUISTA

De Sade, Marqués (n.d.). Filosofía en el tocador. Recuperado de http://losdependientes.com.ar/uploads/sucj31sdk.pdf

De Sade, Marqués (n.d.). Justine. Recuperado de

http://seronoser.free.fr/sade/1788\%20Justine.pdf

Díaz del Castillo, Bernal (n.d.). Historia verdadera de la conquista de la Nueva España (n.d.). Recuperado de http://www.historiadelnuevomundo.com/docs/Conquista-Nueva-EspanaBernal-Diaz-del-Castillo.pdf

El presidente de Uganda firma la ley que condena a los homosexuales a cadena perpetua. El Mundo. Recuperado de http://www.elmundo.es/internacional/2014/02/24/530b419a22601d1e1c8b457f.html

Fernández de Oviedo, Gonzalo (n.d.) Historia general y natural de las indias. Recuperado de http://www.biblioteca-antologica.org/wpcontent/uploads/2009/09/FERN\%C3\%81NDEZ-DE-OVIEDO-Historia-general-y-natural-I.pdf

Foucault, Michel (n.d.). Historia de la locura en la época clásica. Recuperado de http://foucault.pbworks.com/f/locura1.pdf

Foucault, Michel (n.d.). Historia de la sexualidad. Recuperado de http://www.uruguaypiensa.org.uy/imgnoticias/681.pdf

García Álvarez, Miguel (n.d.). Sentencia de la Inquisición a Galileo. Recuerdos de Pandora. Recuperado de http://recuerdosdepandora.com/personajes/galileo-galilei/sentencia-dela-inquisicion-a-galileo/

Giordano Bruno. Agustín Celis Sánchez. Recuperado de http://www.agustincelis.com/GIORDANO\%20BRUNO.html 
LA VISIÓN DEL OTRO: HOMOSEXUALES INDOANTILLANOS EN LA ÉPOCA DE LA CONQUISTA

Homofobia (n.d.). Diccionario de la Real Academia Española(n.d.). Recuperado de http://buscon.rae.es/drae/srv/search?val=homofobia

Homosexualidad. Diccionario de la Real Academia Española (n.d.). Recuperado de http://buscon.rae.es/drae/srv/search?val=homosexualidad

Is the Catholic Church a Force for Good in the World?: Intelligence Squared. Youtube. Recuperado de http://www.youtube.com/watch?v=TUR4OH7_0PE

La homosexualidad en los animales. Ojocientífico.com. Recuperado de http://www.ojocientifico.com/4247/la-homosexualidad-en-los-animales

Lamourt-Valentín, Oscar (n.d.). Análisis de las crónicas de Pané. Documento no publicado.

Latinismo (n.d.). Wikilengua. Recuperado de http://www.wikilengua.org/index.php/Latinismo

Lilith (n.d.). Wikipedia. Recuperado de http://es.wikipedia.org/wiki/Lilit López Nieves, Léster (6/mayo/2013). Puertorriqueños sodomitas, vagos y parejeros. Garita del Diablo. Recuperado de http://garitadeldiablo.wordpress.com/2013/05/06/puertorriquenos-sodomitas-vagos-y-parejeros/

Martínez Torres, Roberto (n.d.). Catey.

Méndez Caratini, Héctor (n.d.). Petroglifos de Boriquén, 1975-1995. Héctor Méndez Caratini: vídeos y fotografías de Puerto Rico y Latinoamérica. Recuperado de http://hectormendezcaratini.com/2013/fotografias-en-blanco-negro/petroglifos-1975-1995/

Miner Solá, Edwin (2008). Diccionario taíno ilustrado. Ediciones Servilibros Mires, Fernando (2006). La colonización de las almas: misión y conquista en hispanoamérica. Buenos Aires, Argentina: Libros de la Araucaria. 
LA VISIÓN DEL OTRO: HOMOSEXUALES INDOANTILLANOS EN LA ÉPOCA DE LA CONQUISTA

Nefando, da. Diccionario de la Real Academia Española (n.d.). Recuperado de http://buscon.rae.es/drae/srv/search?id=oRBivhg3KDXX23skXUCa

Norniella, Jaime M. (n.d.). Homosexualidad en la Edad Media Española. Recuperado de http://www.islaternura.com/APLAYA/HOMOenHISTORIA/HomoEdadMedia.htm

Ocaña, Juan C. (2011). La conquista musulmana y los pueblos invasores.

Historiasiglo20.org. Recuperado de http://www.historiasiglo20.org/HE/2a.htm

Orientación sexual y homosexualidad. American Psychological Association. Recuperado de http://www.apa.org/centrodeapoyo/sexual.aspx

Pané, Ramón (n.d.). Relación acerca de las antigüedades de los indios. Siglo Veintiuno Editores.

Pellini, Claudio A. (n.d.). Homosexualidad y amor conyugal en la Edad Media. Planeta Sedna. Recuperado de http://www.portalplanetasedna.com.ar/edadmedia5.htm

Piñerúa Monasterio, Félix (8/julio/2013). Cultura Taína- Sistema de Creencias Taína. Antropología y Ecología UPEL. Recuperado de http://antropologiayecologiaupel.blogspot.com/2013/07/cultura-taina-sistema-de-creenciastaina.html

Prado Rosas, Erasmo (16/mayo/2011). La homofobia de Vasco Nuñez de Balboa. Retrato del ser: el lugar donde la humanidad se funde con la cultura y el arte. Recuperado de http://retratodelser.blogspot.com/2011/05/la-homofobia-de-vasco-nunez-de-balboa.html

Same-Sex Marriage Debate: Gallagher vs. Corvino. Youtube. Recuperado de http://www.youtube.com/watch?v=2ZVA0vwHMQs 
LA VISIÓN DEL OTRO: HOMOSEXUALES INDOANTILLANOS EN LA ÉPOCA DE LA CONQUISTA

Rodas, Hilda (11/abril/2012). Sexualidad Precolombina. Espiritualidad Maya en Guatemala. Recuperado de http://espiritualidadmaya.blogspot.com/2012/04/sexualidadprecolombina.html

Shakespeare, William (n.d.). Romeo y Julieta. Recuperado de http://www.edu.mec.gub.uy/biblioteca_digital/libros/s/Shakespeare\%20\%20Romeo\%20y\%20Julieta.pdf

Sodomía. Diccionario de la Real Academia Española (n.d.). Recuperado de http://lema.rae.es/drae/srv/search?id=dBI9fQKJpDXX2wmY3Yu9

Sued Badillo, Jalil (1978) Los Caribes: realidad o fábula. Río Piedras: Editorial Santillana.

Suro, Darío (10/diciembre/ 1969). El arte taíno. América, No.278, pp. 65-68

Todorov, Tzvetan (1989) La conquista de America, el problema del otro.

Tratado sobre las justas causas de la guerra contra los indios. Recuperado de http://elmitodeluno.blogspot.com/2008/06/tratado-sobre-las-justas-causas-de-la.html

Uganda 'homosexuals' named in Red Pepper paper (25/ febrero/ 2014). BBC News:

Africa. Recuperado de http://www.bbc.com/news/world-africa-26338941

Miguel, Veronique (7/octubre/2013). Sexualidad en la cultura precolombina. Recuperado de http://suite101.net/article/sexualidad-en-la-cultura-precolombina-a2579

Viñau Ena, Nacho (8/Julio/2008). Homosexuales en Roma y Grecia. Ambiente G. Recuperado de http://www.ambienteg.com/historia/homosexuales-en-roma-y-grecia

Wahlström, Victor (n.d.) Lo fantástico y lo literario en las Crónicas de Indias. Recuperado de http://lup.lub.lu.se/luur/download?func=downloadFile\&recordOId=1485594\&fileOId=1497036 